\title{
STUDY ON ANTIMICROBIAL ACTIVITY OF A FOOD PACKAGING MATERIAL CONTAINING POTASSIUM SORBATE
}

\author{
F. DeVlieghere ${ }^{\text {a }}$, L. Vermeiren, A. Bockstal and J. DebeVere \\ Department of Food Technology and Nutrition, \\ Laboratory of Food Microbiology and Food Preservation, University of Gent, \\ Coupure links 653, B-9000 Gent. Belgium
}

(Received: 13 September 1999; accepted: 8 December 1999)

\begin{abstract}
The feasibility of EVA/LLDPE films containing 1, 2 and $5 \%$ (w/w) K-sorbate to inhibit microbial growth and as a consequence prolong shelf-life of foods was investigated. Based on weight loss experiments it was shown that K-sorbate is very suitable for incorporation in LLDPE because of its heat stability during extrusion. After 3 weeks, resp. 6.4, 2.8 and $5.7 \%$ of the incorporated sorbic acid was released into distilled water from films containing resp. 1, 2 and 5\% $(\mathrm{w} / \mathrm{w}) \mathrm{K}$-sorbate. The very limited migration of K-sorbate may be explained by the incompatibility of the polar salt with the apolar LLDPE. This limited migration could explain the very small inhibitory effect of the K-sorbate films on the growth of Candida spp., Pichia spp., Trichosporon spp. and Penicillium spp. During storage at $7{ }^{\circ} \mathrm{C}$ of cheese packaged in a $5 \%(\mathrm{w} / \mathrm{w}) \mathrm{K}$-sorbate film, no significant differences could be observed for yeast and mould growth on the cheese cubes compared to a reference film. The concentration of sorbic acid in the cheese did not exceed $14 \mathrm{ppm}$. This is much lower than the $1000 \mathrm{ppm} \mathrm{K}$-sorbate needed to inhibit microbial growth. The results of this study confirm that the K-sorbate incorporated LLDPE film is not able to inhibit microbial growth in vitro on inoculated media and in vivo on cheese due to the insufficient release of K-sorbate from the film.
\end{abstract}

Keywords: active packaging, antimicrobial, migration, potassium sorbate

Active packaging is a relatively novel concept that can be defined as a type of packaging that changes the condition of the packaged food to extend its shelf-life or improve its safety or sensory properties. Reviews about the most important types of active packaging concepts were given by VERMEIREN et al. (1999), NIELSEN (1997), ROONEY (1995) and LABUZA and BREENE (1989). To control undesirable development of micro-organisms at the surface of foods, active packaging materials containing antimicrobial components might be used. These materials contain within their mass or on their surface a preservative which can migrate partly or completely into the food and exercise its preservative action there (LÜCK \& JAGER, 1997). Major food applications

a To whom the correspondence should be addressed

Phone: ++329264 61 78; Fax: ++329225 55 10; E-mail: Frank.Devlieghere@rug.ac.be 
for antimicrobial films include meat, fish, bread, cheese, fruit and vegetables (LABUZA \& BREENE, 1989; FLOROS et al., 1997). Several compounds have been proposed and/or tested for antimicrobial activity in food packaging including Ag-substituted zeolite (ISHITANI, 1995), organic acids such as sorbate, propionate and benzoate (HAN \& FLOROS, 1997) or the respective acid anhydrides (WENG \& CHEN, 1997), bacteriocins e.g. nisin and pediocin (DOBIAS et al., 1999; MING et al., 1997), enzymes such as lysozyme (PADGETT, 1998; APPENDINI \& HOTCHKISS, 1997) and fungicides such as benomyl (HALEK \& GARG, 1989) and imazalil (WENG \& HOTCHKISS, 1992). Many of the antimicrobial compounds studied are either not permitted for food application or need to migrate to the food to be effective (APPENDINI \& HOTCHKISS, 1997). The choice of the antimicrobial compound is often limited by the incompatibility of the component with the packaging material or by the heat lability of the component during extrusion (HAN \& FLOROS, 1997, WENG \& HOTCHKISS, 1993). Sorbic acid and its potassium salt, generally known as sorbates, have been used for many years as antimicrobial preservatives in a wide range of foods. The antimicrobial activity of sorbate, which is not as comprehensive against bacteria as against yeasts and moulds, is pH-dependent. As the microbial cell is negatively charged, only the undissociated sorbate molecule can diffuse into the cell to dissociate and exert an antimicrobial activity. At neutral or slightly low $\mathrm{pH}$, the dissociation degree of sorbate is high and consequently less sorbate diffuses into the cell to exert an antimicrobial activity (SOFOS \& BUSTA, 1981). The use of sorbic acid and sorbates in food is permitted in all countries of the world. Methods of application of sorbate include direct addition into the product, dipping or spraying with a sorbate solution and incorporation in the wrapping or packaging material (SOFOS \& BUSTA, 1981). HAN and FLOROS (1997) showed that 1\% potassium sorbate in a low density polyethylene (LDPE) film inhibited the growth of Saccharomyces spp. on agar plates. The LDPE resin and potassium sorbate powder can be mixed, extruded and pelletized to produce a masterbatch. These masterbatch pellets can then be added to LDPE resin. The masterbatch should be produced at low temperature to prevent heat decomposition of the potassium sorbate (HAN \& FLOROS, 1997). The study of HAN and FLOROS (1997) is in contradiction with the results of WENG and HOTCHKISS (1993), which tested also LDPE films with up to $1 \%(\mathrm{w} / \mathrm{w})$ incorporated sorbic acid. The films failed to inhibit mould growth when brought into contact with inoculated media. According to WENG and HOTCHKISS (1993), the sorbic acid was insufficiently released from the film to be antimycotic because of the incompatibility of the polar sorbate with the apolar LDPE. This contradiction of results was not investigated in further research work.

The objective of this work was to quantitatively determine (a) the migration of potassium sorbate (K-sorbate) from $\mathrm{K}$-sorbate containing films in distilled water to determine the rate and maximum level at which $\mathrm{K}$-sorbate migrates in a food simulant, 
(b) the effect of K-sorbate films on the in-vitro growth of yeasts and moulds typically for cheese, (c) the effect of K-sorbate films on the microbial shelf-life of cheese and (d) simultaneously the migration behaviour of sorbic acid in the surface and centre of the packaged cheese.

\section{Materials and methods}

\subsection{Preparation of $K$-sorbate containing films}

K-sorbate was incorporated by A. Schulman Plastics N.V. (Bornem, Belgium) in EVA/LLDPE (ethylene vinyl alcohol/linear low density polyethylene) films $(70 \mu \mathrm{m})$. Films containing 10000,20000 and $50000 \mathrm{ppm}$ or 1,2 and $5 \%(\mathrm{w} / \mathrm{w}) \mathrm{K}$-sorbate were prepared.

\subsection{Heat stability of K-sorbate}

Weight loss tests were performed for K-sorbate powder to determine the percentage K-sorbate which volatilises at the extrusion temperature (about $230^{\circ} \mathrm{C}$ ). For these tests a Dupont Instruments 951 Thermogravimetric Analyzer (951 TGA) was used, connected to a computer to record the weight. A small sample (max. $40 \mathrm{mg}$ ) was heated up to $600{ }^{\circ} \mathrm{C}$ under $\mathrm{N}_{2}$ at a rate of 10 to $20{ }^{\circ} \mathrm{C} \mathrm{min}^{-1}$. The 951 TGA measures by means of two photodiodes the rate of weight change of the sample as a function of increasing temperature. Weight loss occurs through evaporation of volatile compounds present in the sample and/or through decomposition of the product.

\subsection{Migration of $K$-sorbate in distilled water}

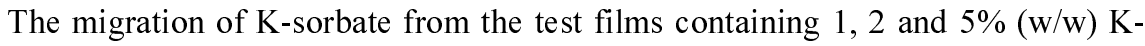
sorbate and from a reference film containing no K-sorbate was investigated by immersing 5 pieces $(5 \times 8.5 \mathrm{~cm})$ of the test films into $300 \mathrm{ml}$ of water within a closed system. The test was carried out in distilled water and in buffered $\left(0.2 \mathrm{~mol} \mathrm{l}^{-1}\right.$

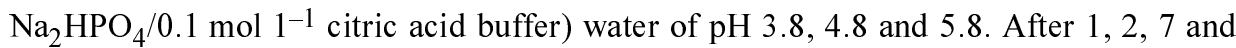
21 days the level of migrated sorbic acid was determined by analysing $100 \mathrm{ml}$ of the water. Experiments were carried out in duplicate.

\subsection{Analytical method for determination of sorbic acid in water}

Hundred $\mathrm{ml}$ of sample was transferred into a $500 \mathrm{ml}$ separation funnel and $2 \mathrm{ml}$ $9 \mathrm{~mol} \mathrm{l}^{-1} \mathrm{H}_{2} \mathrm{SO}_{4}$ and $1 \mathrm{ml}$ of $0.1 \%(\mathrm{w} / \mathrm{v})$ parahydroxybenzoic acid as internal standard were added. The acidification is essential for converting $\mathrm{K}$-sorbate to sorbic acid. The mixture was extracted twice with $50 \mathrm{ml}$ of diethylether. The ether extract was washed 
with $20 \mathrm{ml}$ of distilled water, filtered over $\mathrm{Na}_{2} \mathrm{SO}_{4}$ and evaporated in a rotavapor. Furthermore, $0.8 \mathrm{ml}$ of dry pyridine, $0.2 \mathrm{ml}$ of bis(silyl)tri-fluoracetamide (BSTFA) and three droplets of trimethylchlorosilane (TMCS) were added to the dry extract (further dried under nitrogen) for the derivatisation step $\left(30 \mathrm{~min}\right.$ at $\left.60^{\circ} \mathrm{C}\right)$. The derivated solutions were further analysed by gas chromatography (GC 8000). Chromatographic conditions were: column Chromapack WCOT fused silica CP-sil $5 \mathrm{CB}$, length $25 \mathrm{~m}$, I.D. $0.32 \mathrm{~mm}$, F.I.D. detector, time of analysis $40 \mathrm{~min}$, injection volume $1 \mu \mathrm{l}$.

\subsection{Effect of K-sorbate film on the growth of yeasts and moulds}

Three different types of OGA (Diagnostics, Pasteur) plates (pH 3.8, 4.8 and 5.8) were inoculated with approximately $10^{3}$ cells of either Candida spp., Pichia spp. or Trichosporon spp. by the spread plate method and by the pour plate method. PDA plates (Oxoid CM 139) were inoculated with $0.1 \mathrm{ml}$ of spore suspension $\left(10^{2}\right.$ spores) of Penicillium spp. In both cases, petri dishes were filled with medium to the edge. The inoculated plates were covered with a packaging film containing 5\% (w/w) K-sorbate. Reference films containing no K-sorbate were used as controls. The covered OGA plates were vacuum packaged in a plastic bag (VPA/PE 15-60 Sudpack, Verpackungen Ochsenhowsen, Germany, OTR $=2.5 \mathrm{ml} \mathrm{m}^{-2} 24 \mathrm{~h}^{-1} \mathrm{~atm}^{-1}$ at $20{ }^{\circ} \mathrm{C}$ and $70 \% \mathrm{RV}$ ) to ensure the contact between the film and the inoculated surface. Plates were stored at $7{ }^{\circ} \mathrm{C}$ and at regular times visually inspected for growth of yeasts and moulds. Experiments were carried out in duplicate.

\subsection{Effect of $K$-sorbate film on the shelf-life of cheese}

Cheese cubes $(10 \times 4 \times 1.2 \mathrm{~cm}$ and free of sorbic acid) were vacuum packaged in films in which $5 \%(\mathrm{w} / \mathrm{w}) \mathrm{K}$-sorbate was incorporated as well as in films containing no $\mathrm{K}$-sorbate. Vacuum packaging was necessary to ensure that the packaging film was in direct contact with the surface of the cheese. Because LLDPE films are permeable to $\mathrm{O}_{2}$, that will diffuse through the film and no real vacuum is created. During storage at $7{ }^{\circ} \mathrm{C}$ the growth of yeasts and moulds on the cheese cubes was followed. Simultaneously, the amount of K-sorbate released from the film into the cheese was determined. After $0,1,3,5$ and 7 weeks yeasts were determined by spreadplating a dilution series of a cheese sample in PPS (physiological peptone solution) on OGA (Diagnostics, Pasteur). The growth of Penicillium spp. was visually detected through the packaging film. After $0,1,3,5$ and 7 weeks the level of sorbic acid present in the outer $2 \mathrm{~mm}$ and at the centre of the cheese cubes was determined. 


\subsection{Analytical method for determination of $K$-sorbate in cheese}

Ten grams of homogeneous sample was brought into a $250 \mathrm{ml}$ Erlenmeyer flask and $2 \mathrm{ml}$ of $9 \mathrm{~mol} \mathrm{l}^{-1} \mathrm{H}_{2} \mathrm{SO}_{4}$ and $1 \mathrm{ml}$ of $0.1 \%(\mathrm{w} / \mathrm{v})$ parahydroxybenzoic acid as internal standard were added. The mixture was extracted twice with $30 \mathrm{ml}$ of diethylether. The extracts were then transferred into a separation funnel and washed with $20 \mathrm{ml}$ of distilled water. This procedure was followed by a twofold extraction of the ether phase with $20 \mathrm{ml}$ of $0.1 \mathrm{~mol}^{-1} \mathrm{NaOH}$ and $10 \mathrm{ml}$ of saturated $\mathrm{NaCl}$ solution. The acidified $\left(2.5 \mathrm{ml}\right.$ of $\left.4 \mathrm{~mol} \mathrm{l}^{-1} \mathrm{HCl}\right) \mathrm{NaOH}$ extracts were then extracted twice with $30 \mathrm{ml}$ of diethylether. The ether extracts were filtered over $\mathrm{Na}_{2} \mathrm{SO}_{4}$, evaporated in a rotavapor and dried under $\mathrm{N}_{2}$. The derivatisation step and the gas chromatographic analysis were identical to the determination of $\mathrm{K}$-sorbate in water.

\section{Results and discussion}

\subsection{Heat stability of $K$-sorbate}

The result of the weight loss experiment is presented as percentage weight retention or $100 \times$ (weight after heating/initial weight) as a function of increasing temperature (Fig. 1). At the extrusion temperature (about $230^{\circ} \mathrm{C}$ ) a weight loss of $1.43 \%$ was observed. The weight loss remained constant, while temperature was further increased. Apparently, during extrusion only small losses of K-sorbate will occur, which is beneficial for incorporation of the antimicrobial compound into a packaging material.

\subsection{Migration of K-sorbate into water}

The results of the migration tests are presented as $\mu \mathrm{g}$ sorbic acid $\mathrm{g}^{-1}$ film as a function of time (Fig. 2). For the films which contained resp. 1 and $2 \%(\mathrm{w} / \mathrm{w}) \mathrm{K}$-sorbate, a maximum amount of migrated sorbate (resp. 442 and $716 \mu \mathrm{g} \mathrm{g}^{-1}$ film) was reached already after 2 days. The migration from the $5 \%(\mathrm{w} / \mathrm{w}) \mathrm{K}$-sorbate film didn't reach a maximum after 3 weeks. After 1 day, $1040 \mu \mathrm{g}$ sorbic acid g ${ }^{-1}$ film was migrated, while after 3 weeks the level of migrated sorbate was increased to $2833 \mu \mathrm{g} \mathrm{g}^{-1}$ film. When the level of migrated sorbate is compared to the initial level of $\mathrm{K}$-sorbate incorporated in the film, resp. 6.4, 2.8 and $5.7 \%$ of the incorporated K-sorbate was released after 3 weeks from the films containing resp. 1, 2 and $5 \% \mathrm{~K}$-sorbate. The migration is very low, especially when it is taken into account that in contrast with packaged foods the migration occurred at both sides of the film. The low migration of K-sorbate could be explained by the incompatibility of the polar sorbate with the apolar LLDPE film (WENG \& HOTCHKISS, 1993). No significant differences were found in the level of sorbic acid released into water of different $\mathrm{pH}(3.8,4.8$ and 5.8) (Fig. 3). To estimate 
the amount of sorbic acid which would migrate as a function of time, the following example can be calculated. Consider $100 \mathrm{~g}$ of a food product with a surface area of $2 \mathrm{dm}^{2}$, packaged in a film which contains $5 \%(\mathrm{w} / \mathrm{w}) \mathrm{K}$-sorbate. Assuming that the migration from the film into the food product is the same as into distilled water, the amount of migrated K-sorbate after resp. 7 and 21 days is resp. about 15 and $40 \mathrm{ppm}$ $\mathrm{K}$-sorbate. This is a very small quantity because earlier results (not shown here) made clear that at least $1000 \mathrm{ppm} \mathrm{K}$-sorbate needs to migrate from the films to inhibit microbial growth.

\subsection{Effect of K-sorbate film on the growth of yeasts and moulds}

For the inoculated spread and pour plates covered with a film containing $5 \%$ (w/w) K-sorbate, a very low inhibition of the growth of Candida spp., Pichia spp. and Trichosporon spp. was observed in comparison with the reference film (no K-sorbate). For all yeasts, growth was delayed one day by covering the inoculated plates with the $5 \%(\mathrm{w} / \mathrm{w}) \mathrm{K}$-sorbate film compared to the reference film. During growth, however, no significant differences could be observed between films. The same results were obtained for Penicillium spp. Furthermore, no significant differences were found in the yeast and mould growth between plates of different $\mathrm{pH}$ (3.8, 4.8 and 5.8).

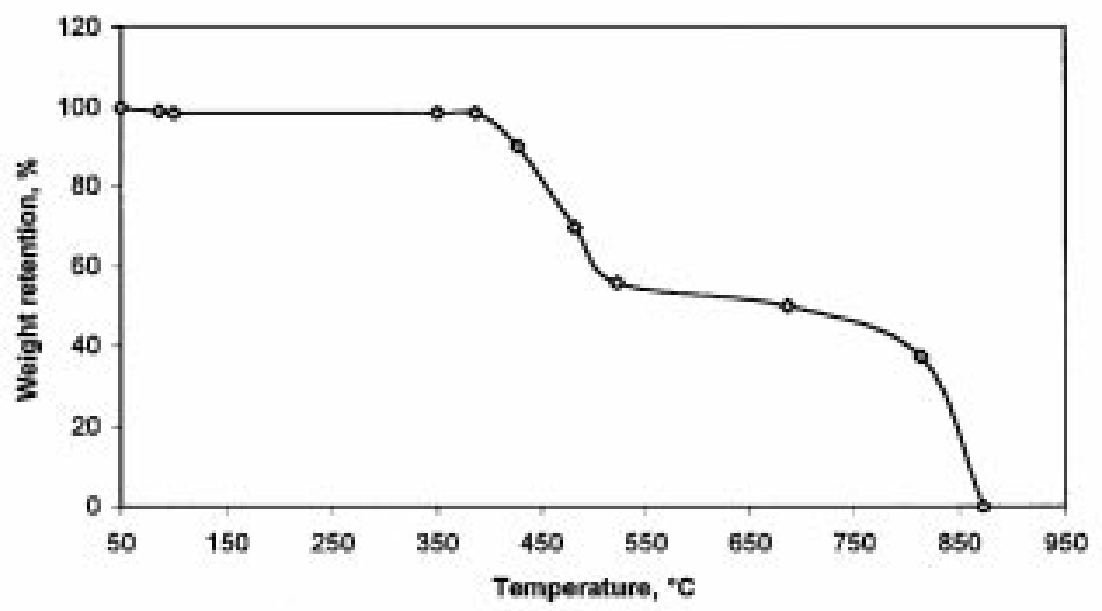

Fig. 1. Percentage weight retention, expressed as $100 \times$ (weight after heating/initial weight) of a $20.5539 \mathrm{mg}$ $\mathrm{K}$-sorbate sample as a function of increasing temperature 


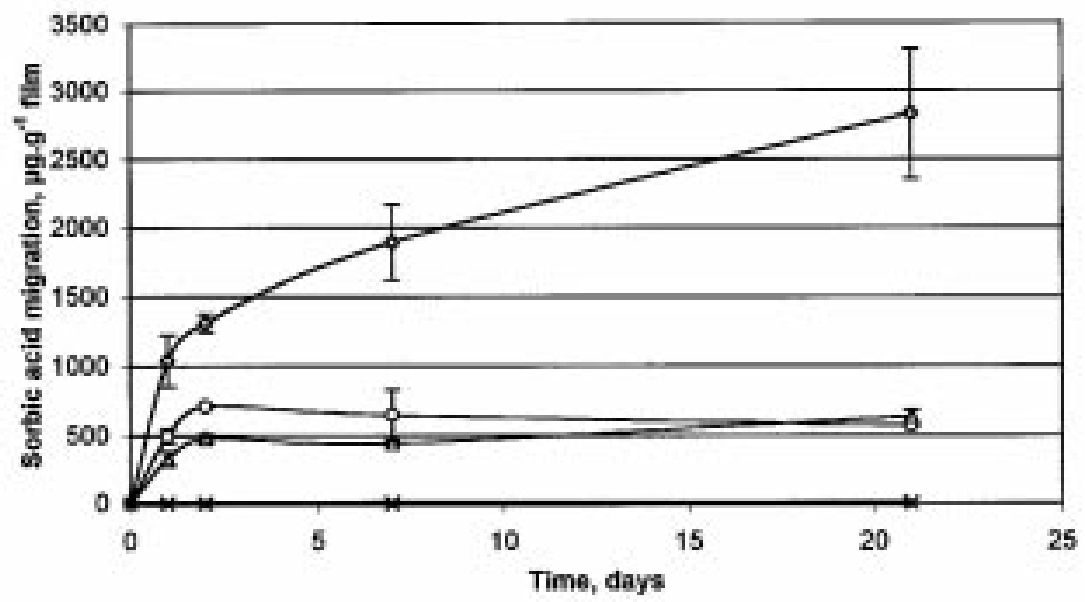

Fig. 2. The migration of K-sorbate into distilled water from films containing $0(\times), 1(\Delta), 2$ (o) and $5(\diamond) \%(w / w)$ K-sorbate, expressed as $\mu \mathrm{g}$ sorbic acid g ${ }^{-1}$ film

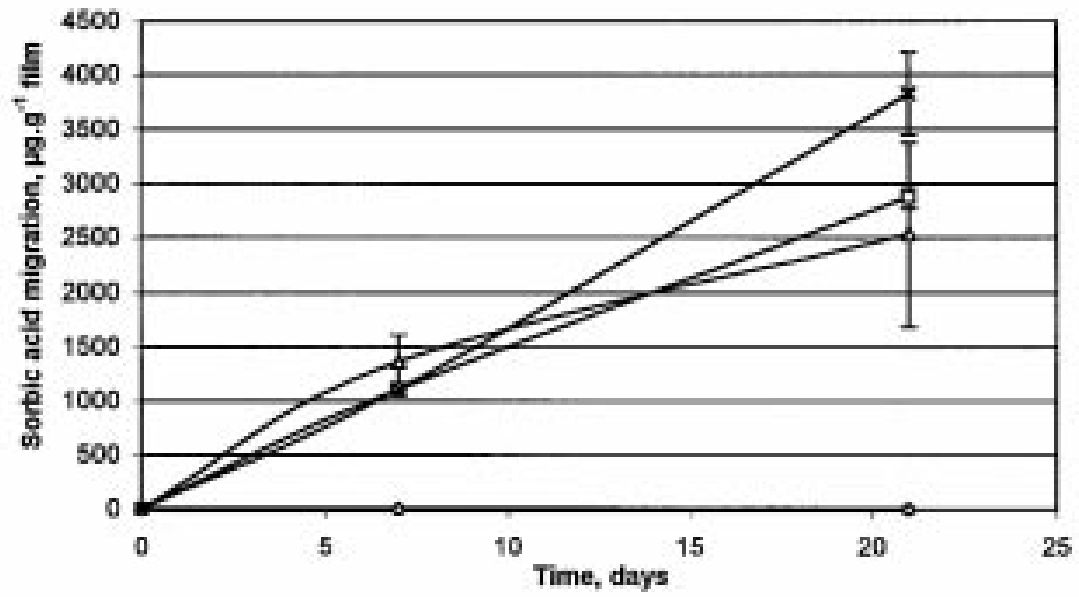

Fig. 3. The migration at pH $3.8(\square), 4.8(\Delta)$ and $5.8(\times)$ of K-sorbate into distilled water from a film containing $5 \%(\mathrm{w} / \mathrm{w})$ K-sorbate in comparison to a reference $(0 \%$ K-sorbate $)$ film $(\diamond)$, expressed as $\mu \mathrm{g}$ sorbic acid $\mathrm{g}^{-1}$ film 


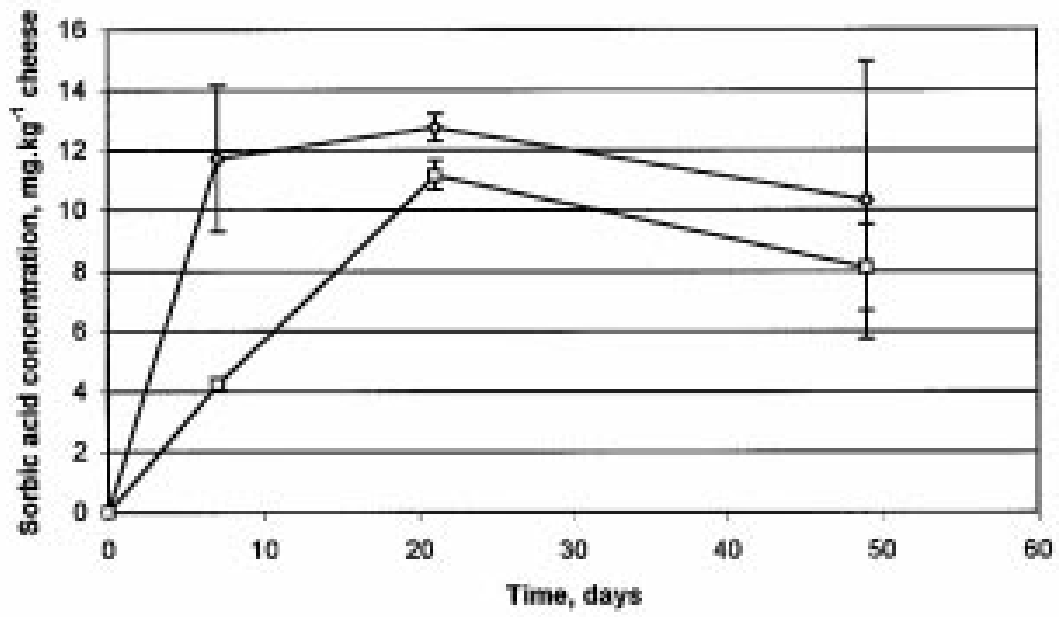

Fig. 4. The amount of sorbic acid released from a LLDPE film containing $5 \%(\mathrm{w} / \mathrm{w}) \mathrm{K}$-sorbate into the surface $(\diamond)$ and the centre $(\square)$ of cheese cubes as a function of time, expressed as mg sorbic acid kg-1 cheese

The low inhibitory effect of the K-sorbate films on the yeast and mould growth could be expected as the migration of K-sorbate from the films into water was very limited. The results for the mould growth correspond with these reported by WENG and HOTCHKISS (1993). These authors also failed to demonstrate inhibition of Penicillium growth when inoculated media were brought into contact with $1 \% \mathrm{~K}$-sorbate incorporated LDPE. The results for yeast (Candida, Pichia and Trichosporon spp.) growth, however, do not correspond with the results of HAN and FLOROS (1997), which succeeded to demonstrate a limited inhibition of another yeast (Saccharomyces) species by a $1 \% \mathrm{~K}$ sorbate LDPE film.

\subsection{Effect of $K$-sorbate film on the shelf-life of cheese}

No significant differences could be observed for the yeast growth between cheese cubes packaged in a $5 \%(\mathrm{w} / \mathrm{w}) \mathrm{K}$-sorbate film and cheese cubes packaged in the reference film. This result could be expected due to the very limited migration from sorbate into water and due to the fact that at $\mathrm{pH} 5.8$ ( $\mathrm{pH}$ of the cheese) only $7 \%$ of the released sorbic acid is present in the undissociated form (SOFOS \& BUSTA, 1981). For the visual detection of the moulds on the cheese cubes, similar results were obtained. The amount of sorbic acid that migrated into the cheese cubes is presented in Fig. 4. During 21 days the concentration of the released sorbic acid increased both at the surface and in the centre of the cheese. During these 3 weeks a significantly higher 
concentration of sorbic acid could be detected in the outer $2 \mathrm{~mm}$ of the cheese than in the centre of the cheese. The concentration of sorbic acid detected in the cheese did not reach more than $14 \mathrm{ppm} \mathrm{K}$-sorbate. This is much lower than the $1000 \mathrm{ppm} \mathrm{K}$-sorbate needed in earlier experiments (results not shown here) to inhibit microbial growth.

\section{Conclusions}

The weight loss experiment showed that $\mathrm{K}$-sorbate is a feasible antimicrobial compound to incorporate in packaging material because of the small weight losses during extrusion. A very limited migration of $\mathrm{K}$-sorbate in to water as well as into cheese cubes was observed probably because of the incompatibility of the polar salt with the apolar LDPE, as suggested by WENG and HOTCHKISS (1993). Due to this insufficient migration, the packaging film showed only a very small inhibitory effect on the in vitro growth of yeasts and moulds as well as on the yeast and mould growth on cheese cubes, packaged in a $5 \%(\mathrm{w} / \mathrm{w}) \mathrm{K}$-sorbate film and stored at $7{ }^{\circ} \mathrm{C}$. The results of this study confirm that the K-sorbate incorporated LLDPE film is not able to inhibit the growth of micro-organisms on cheese and thereby prolong shelf-life.

The technical support by A. Schulman Plastics N.V. is gratefully acknowledged.

\section{References}

APPENDINI, P. \& HOTCHKISS, J. H. (1997): Immobilisation of lysozyme on food contact polymers as potential antimicrobial films. Packag. Technol. Sci., 10, 271-279.

DOBIAS, J., VOLDRICH, M., MAREK, M., CEROVSKY, M. \& ChUDACKOVA, K. (1999): Active packaging immobilisation of preservatives on/in polymer packaging materials. Proceedings of the third European symposium on sous vide. KUL, Belgium, March 25-26, p. 70.

FloroS, J. D., DOCK, L. L. \& HAN, J. H. (1997): Active packaging technologies and applications. Fd Cosmet. Drug Packag., 20, 10-17.

HALEK, W. \& GARG, A. (1989): Fungal inhibition by a fungicide coupled to an ionomeric film. J. Fd Safety, 9, 215-222.

HAN, J. H. \& FLOROS, J. D. (1997): Casting antimicrobial packaging films and measuring their physical properties and antimicrobial activity. J. Plastic Film Sheeting, 13, 287-298.

ISHITANI, T. (1995): Active packaging for food quality preservation in Japan. -in: ACKERMAN, P., JÄGERSTAD, M. \& OHLSSON, T. (Eds.), Foods and packaging materials-chemical interactions. Royal Society of Chemistry, Cambridge, pp. 177-188.

LABUZA, T. P. \& BREENE, W. M. (1989): Applications of active packaging for improvement of shelf-life and nutritional quality of fresh and extended shelf-life foods. J. Fd Process. Preserv., 13, 1-69. 
LÜCK, E. \& JAGER, M. (1997): Antimicrobial food additives: Characteristics, uses, effects. Springer, Berlin, p. 255 .

Ming, X., WEBER, G. H., AYRES, J. W. \& SANDINE, W. E. (1997): Bacteriocins applied to food packaging materials to inhibit Listeria monocytogenes on meats. J. Fd Sci., 62, 413-415.

NIELSEN, T. (1997): Active packaging - a literature review. SIK-Rapport nr 631, $20 \mathrm{p}$.

PADGETT, T., HAN, I. Y. \& DAWSON, P. L. (1998): Incorporation of food-grade antimicrobial compounds into biodegradable packaging films. J. Fd Prot., 61, 1130-1335.

ROONEY, M. L. (1995): Active food packaging. Blackie Academic \& Professional, London, 260 pp.

SOFOS, J. N. \& BUSTA, F. F. (1981): Antimicrobial activity of sorbate. J. Fd Prot., 44, 614-622.

VermeIREN, L., DeVlieghere, F., VAN BeEst, M., DE KruiJf, N. \& DEBEVERE, J. (1999): Developments in the active packaging of foods. Trends Fd Sci Technol., 10 (3), 77-86.

WENG, Y. M. \& CHEN, M. J. (1997): Sorbic anhydride as antimycotic additive in polyethylene food packaging films. Fd Sci. Technol., 30, 485-487.

WENG, Y. M. \& HOTCHKISS, J. H. (1992): Inhibition of surface moulds on cheese by polyethylene film containing the antimycotic imazalil. J. Fd Prot., 55, 367-369.

WENG, Y. M. \& HOTCHKISS, J. H. (1993): Anhydrides as antimycotic agents added to polyethylene films for food packaging. Packaging Technol. Sci., 6, 123-128. 